\title{
Risk of second primary Cancer among bladder Cancer patients: a population- based cohort study in Korea
}

Whi-An Kwon ${ }^{1 \dagger}$, Jae Young Joung ${ }^{1 \dagger}$, Jiwon Lim², Chang-Mo Oh², Kyu-Won Jung ${ }^{2}$, Sung Han Kim', Ho Kyung Seo ${ }^{1}$, Weon Seo Park', Jinsoo Chung ${ }^{1}$, Kang Hyun Lee ${ }^{1}$ and Young-Joo Won ${ }^{2 *}$

\begin{abstract}
Background: For the expanding population of bladder cancer survivors in Korea, the development of subsequent cancers is a significant concern. Here, we provide the second primary cancer incidence rates and types in Korean patients with bladder cancer.

Methods: Using population-based data from the Korea Central Cancer Registry from 1993 to 2013, we studied the standardized incidence ratios among 48,875 individuals with an initial diagnosis of bladder cancer. Standardized incidence ratios for second primary cancers were evaluated according to age at diagnosis, latency, diagnostic year, and treatment.

Results: Over the same period, the overall risk of a second primary cancer was reduced by $6 \%$ in patients with bladder cancer compared with the development of a new malignancy in the general population (standardized incidence ratio $=0.94 ; 95 \% \mathrm{Cl}, 0.91-0.97, p<0.05)$. For specific cancers, the standardized incidence ratios for stomach, colon, liver, and non-Hodgkin lymphoma were significantly lower in patients with bladder cancer. However, the risk of prostate and kidney cancer in patients with bladder cancer were significantly increased. The risk of lung squamous cell carcinoma and lung adenocarcinoma as second primary cancers was significantly elevated in patients with bladder cancer.

Conclusion: Korean patients with bladder cancer have a $6 \%$ lower risk of developing a second primary cancer. However, they have a higher risk of developing subsequent prostate and kidney cancers, lung squamous cell carcinoma, and lung adenocarcinoma, suggesting the need for continual intensive cancer surveillance among bladder cancer survivors.
\end{abstract}

Keywords: Bladder cancer, Second primary cancer, Prognosis, Incidence, Survival

\section{Background}

Bladder cancer $(\mathrm{BC})$ is the 9th most frequent cancer worldwide [1] and the number of $\mathrm{BC}$ cases increased from 2180 in 1999 to 3549 in 2011, with 37,950 total cases during this period in Korea [2]. Moreover, according to the Korea Central Cancer Registry (KCCR) report, 3949 new BC cases were diagnosed in 2014, with 7.8 cases per 100,000 person-years [3].

\footnotetext{
* Correspondence: astra67@ncc.re.kr

${ }^{\dagger}$ Whi-An Kwon and Jae Young Joung contributed equally to this work.

${ }^{2}$ Cancer Registration and Statistics Branch, National Cancer Center, Goyang, Korea

Full list of author information is available at the end of the article
}

There is a long-term survival concern in patients with $\mathrm{BC}$, especially those with second primary cancer (SPC). For Western patients, compared with the general population, BC survivors are more likely to develop SPCs, which frequently occur in the lungs or neck $[4,5]$. However, to our knowledge, no studies have evaluated SPC among Asian patients with BC. Although, we have previously detailed the overall risk of SPC development in Korean patients with prostate cancer and kidney cancer $[6,7]$. Therefore, we were also interested in studying SPC in patients with primary BC.

The purpose of this population-based cohort study was to calculate the incidence of SPC in Korean patients

(c) The Author(s). 2018 Open Access This article is distributed under the terms of the Creative Commons Attribution 4.0 International License (http://creativecommons.org/licenses/by/4.0/), which permits unrestricted use, distribution, and 
with BC and to estimate the effect of SPC on survival using a nationwide population-based cancer registry. The primary goal was to produce useful data for managing patients with $\mathrm{BC}$.

\section{Methods}

\section{Study population and data collection}

A total of 48,875 patients diagnosed with BC were evaluated between 1993 and 2013 as documented in the KCCR. The KCCR gathers information on $\sim 80-90 \%$ of cancer cases across 180 hospitals across South Korea. In 1999, the scope of the KCCR was expanded to cover the entire South Korean population using the Population-Based Cancer Registry Program [8].

To ensure that SPC remains distinct from primary BC recurrences and metastases, the KCCR uses coding rules based on the histological or topographical classifications of the International Classification of Diseases for Oncology 3rd edition [9] and the International Agency for Research on Cancer (IARC) rules for multiple primary cancer in 2004 [10]. The IARC classifies cancer as an SPC when a primary tumor has a different histological type or anatomical site from the indexed cancer. KCCR data includes patient information (age at the time of diagnosis and sex), cancer information (diagnosis date, tumor site, histology, and surveillance, epidemiology, and end results [SEER] summary stage), and primary treatment information (surgery, chemotherapy, or radiotherapy).

The first primary $\mathrm{BC}$ included patients with a single primary $\mathrm{BC}$ and the first $\mathrm{BC}$ in patients with multiple primary cancers. We excluded the following first primary BC cases: 1) age at diagnosis, unknown; and 2) $\mathrm{BC}$ reported at death. In addition, because SPCs diagnosed within two months of the first primary cancer diagnosis are considered synchronous, these cases were excluded to reduce the misclassification of undetected synchronous cancers and metastases.

Ethical approval for the research protocol was provided by the institutional review board of the National Cancer Center (NCC2017-0182).

\section{Statistical analyses}

Standardized incidence ratios (SIR) were used to compare the relative risk of the SPC incidence rates with those of the general population at baseline. We estimated cancer incidence for each cancer type according to age at diagnosis, latency, and diagnostic year, which was multiplied by the cumulative number of years at risk to calculate the number of cancer outbreaks expected for each stratum. SIR was estimated by dividing the observed number of SPCs in patients with $\mathrm{BC}$ by the number of patients at risk of developing a new malignancy in the general population. The 95\% confidence intervals for the SIRs were estimated using Byar's exact approximation to the accurate Poisson distribution of the observed number. The person-years at risk were calculated from two months after the initial $\mathrm{BC}$ diagnosis until death, the date of last known survival, or the study completion date (December 31st, 2013).

Results were classified based on age at the time of initial diagnosis with $\mathrm{BC}(0-39,40-59$, or $\geq 60$ years $)$, year of first BC diagnosis (1993-2000 or 2001-2013), latency time among first $\mathrm{BC}$ diagnosis and subsequent primary cancer (<12 months, 12-59 months, 60-119 months, or $\geq 120$ months), and treatment type (surgery vs. non-surgery, chemotherapy vs. non-chemotherapy, and radiotherapy $[\mathrm{RT}]$ vs. non-RT).

Survival curves using the Kaplan-Meier method were calculated for BC patients with or without a subsequent cancer. The log-rank test was employed to verify the difference between groups of survival curves. All of the statistical tests were determined statistically significant at $P$-value $<0.05$, and were two-sided. The SIR and $95 \%$ CI calculations were performed using SEER*Stat (seer.cancer.gov/seerstat, version 8.3.4). Survival analyses and log-rank tests were performed using STATA (StataCorp LP, version 12.1).

\section{Results}

We obtained data from 48,875 patients, including 39,351 men (80.5\%) and 9524 women (19.5\%), with a median age at diagnosis of 67 years. The cohort characteristics are shown in Table 1. The overall SPC risk decreased by $6 \%$ in patients with previous $\mathrm{BC}$ compared with that in the general population over the same period $(\mathrm{SIR}=0.94$; 95\% CI, 0.91-0.97). Patients examined within one year of $\mathrm{BC}$ diagnosis exhibited an increased risk of all subsequent cancers $(\mathrm{SIR}=1.21)$. Patients who were followed up for 1-5 years showed a SIR risk reduction of 0.89 . Finally, after $\mathrm{a} \geq 10$-year follow-up, the SIR decreased to 0.86 . Patients aged $<40$ years at $\mathrm{BC}$ diagnosis were more likely to have all SPC types (SIR $=1.50)$; whereas, those aged $40-59$ or $\geq 60$ years at diagnosis exhibited a reduced SPC incidence (SIR $=1.04$ and 0.90 , respectively). Two periods were analyzed (1993-2000 and 2001-2013) to evaluate the potential impact of changes in diagnosis and treatment. SPC incidence differed between these two periods (SIR $=0.85$ and 0.99 , respectively; Table 2).

Significantly lower SIRs were observed for cancers of the tongue $(\mathrm{SIR}=0.37 ; 95 \% \mathrm{CI} 0.10-0.94)$, tonsil $(\mathrm{SIR}=0.27$; 95\% CI 0.03-0.99), stomach (SIR $=0.79$; 95\% CI 0.73-0.86), colon $(\mathrm{SIR}=0.84 ; 95 \% \mathrm{CI} 0.74-0.95)$, and liver $(\mathrm{SIR}=0.79$; 95\% CI 0.69-0.90), and for non-Hodgkin lymphoma $(\mathrm{SIR}=0.69 ; 95 \%$ CI $0.50-0.91)$. However, the risks of prostate cancer and kidney cancer in patients with $\mathrm{BC}$ increased significantly (SIR $=1.46 ; 95 \%$ CI $1.33-1.59$, and SIR $=1.47 ; 95 \%$ CI 1.20-1.79, respectively) (Table 2). 
Table 1 Characteristics of patients with primary BC, 1993-2013

\begin{tabular}{|c|c|c|c|c|c|c|}
\hline & \multicolumn{2}{|l|}{ Total } & \multicolumn{2}{|l|}{ Men } & \multicolumn{2}{|c|}{ Women } \\
\hline & $n$ & $\%$ & $n$ & $\%$ & $n$ & $\%$ \\
\hline Patients with $\mathrm{BC}$ & 48,875 & 100 & 39,351 & 100 & 9524 & 100 \\
\hline \multicolumn{7}{|l|}{ Period of $\mathrm{BC}$ diagnosis } \\
\hline 1993-1997 & 6892 & 14.10 & 5592 & 14.21 & 1300 & 13.65 \\
\hline 1998-2002 & 10,484 & 21.45 & 8377 & 21.29 & 2107 & 22.12 \\
\hline 2003-2007 & 13,585 & 27.80 & 10,942 & 27.81 & 2643 & 27.75 \\
\hline 2008-2013 & 17,914 & 36.65 & 14,440 & 36.70 & 3474 & 36.48 \\
\hline Average age at diagnosis with BC (years; mean, SD) & 65.39 & 12.46 & 64.81 & 12.20 & 67.80 & 13.22 \\
\hline Median age at diagnosis with BC (years; median, range) & 67 & $105(1-106)$ & 66 & $100(1-101)$ & 70 & $105(1-106)$ \\
\hline \multicolumn{7}{|l|}{ Age at primary BC diagnosis (years) } \\
\hline $0-39$ & 1608 & 3.29 & 1259 & 3.20 & 349 & 3.66 \\
\hline $40-59$ & 12,489 & 25.55 & 10,601 & 26.94 & 1888 & 19.82 \\
\hline$\geq 60$ & 34,778 & 71.16 & 27,491 & 69.86 & 7287 & 76.51 \\
\hline \multicolumn{7}{|l|}{ Percentage of primary treatment status } \\
\hline Surgery & 42,448 & 86.85 & 34,653 & 88.06 & 7795 & 81.85 \\
\hline Radiation & 1298 & 2.66 & 1004 & 2.55 & 294 & 3.09 \\
\hline Chemotherapy & 6161 & 12.61 & 5045 & 12.82 & 1116 & 11.72 \\
\hline Average follow-up after BC diagnosis (years; mean, SD) & 5.65 & 5.09 & 5.70 & 5.06 & 5.46 & 5.21 \\
\hline Median follow-up after BC diagnosis (years; median, range) & 4.13 & $20.80(0-20.80)$ & 4.21 & $20.80(0-20.80)$ & 3.67 & $20.80(0-20.80)$ \\
\hline Number of patients who developed a SPC & 3495 & 7.15 & 3116 & 7.92 & 379 & 3.98 \\
\hline Average age at SPC diagnosis (years; mean, SD) & 70.57 & 9.28 & 70.71 & 8.94 & 69.40 & 11.67 \\
\hline Median age at SPC diagnosis (years; median, range) & & $71(10-95)$ & & $71.5(10-95)$ & & $71(12-93)$ \\
\hline $\begin{array}{l}\text { Average interval between primary cancer and SPC } \\
\text { (years; mean, SD) }\end{array}$ & 5.23 & 4.30 & 5.18 & 4.29 & 5.75 & 4.39 \\
\hline $\begin{array}{l}\text { Median interval between primary cancer and SPC } \\
\text { (years; median, range) }\end{array}$ & & $4.17(0.17-0.67)$ & & $4.08(0.17-20.67)$ & & $4.75(0.17-19.08)$ \\
\hline \multicolumn{7}{|c|}{ Number of patients by latency between primary cancer and SPC (years) } \\
\hline 1 & 556 & 15.91 & 469 & 12.95 & 47 & 16.19 \\
\hline $1-4$ & 1409 & 40.31 & 1176 & 39.67 & 144 & 40.61 \\
\hline $5-9$ & 1000 & 28.61 & 813 & 29.20 & 106 & 28.07 \\
\hline$\geq 10$ & 530 & 15.16 & 438 & 18.18 & 66 & 15.12 \\
\hline \multicolumn{7}{|l|}{ Number of patients by age at SPC diagnosis (years) } \\
\hline $0-39$ & 13 & 0.37 & 8 & 0.26 & 5 & 1.32 \\
\hline $40-59$ & 396 & 11.33 & 327 & 10.49 & 69 & 18.21 \\
\hline$\geq 60$ & 3086 & 88.30 & 2781 & 89.25 & 305 & 80.47 \\
\hline Average follow-up after SPC diagnosis, (years; mean, SD) & 2.55 & 2.91 & 2.48 & 2.82 & 3.10 & 3.52 \\
\hline Median follow-up after SPC diagnosis (years; median, range) & 1.42 & $20.00(0-20.00)$ & 1.42 & $20.00(0-20.00)$ & 1.67 & 19.50(0-19.50) \\
\hline \multicolumn{7}{|l|}{ Number of subsequent primary cancers } \\
\hline 1 & 3259 & 6.67 & 2896 & 7.36 & 363 & 3.81 \\
\hline 2 & 217 & 0.44 & 203 & 0.52 & 14 & 0.15 \\
\hline$\geq 3$ & 19 & 0.04 & 17 & 0.04 & 2 & 0.02 \\
\hline
\end{tabular}

$B C$ : bladder cancer, $S D$ : standard deviation, $S P C$ : second primary cancer

Notably, SIR did not increase significantly for total lung cancers. However, a subgroup analysis based on lung cancer histology revealed that the SPC risks of lung squamous cell carcinoma and adenocarcinoma were significantly elevated $(\mathrm{SIR}=1.15 ; 95 \% \mathrm{CI} 1.02-1.29$, and $\mathrm{SIR}=1.20 ; 95 \%$ CI 1.05-1.37, respectively). By contrast, other lung cancer 
Table 2 Risk of SPC after BC diagnosis by follow-up, age, and period (1993-2013)

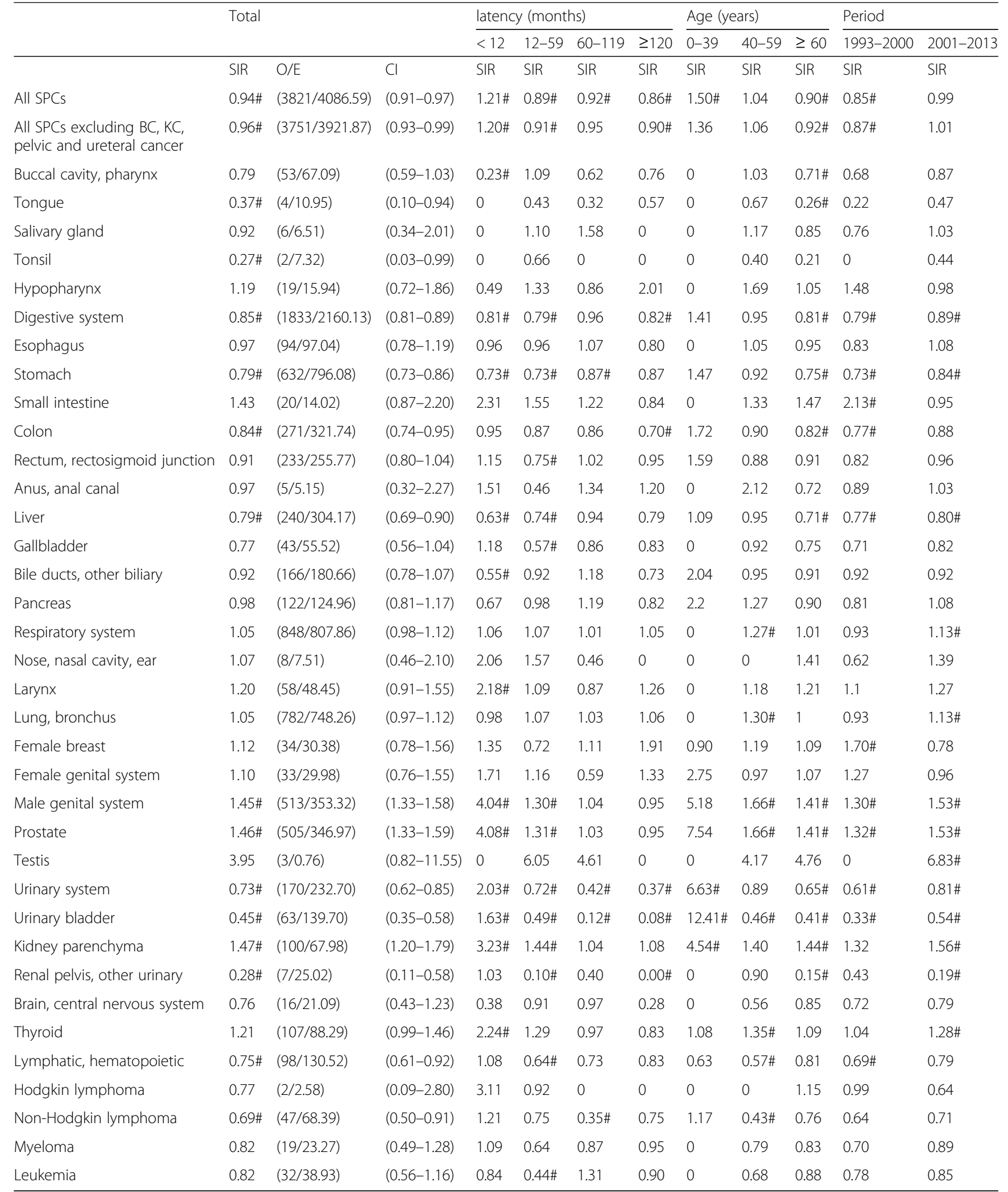


histologies (including small cell carcinoma: $\mathrm{SIR}=1.06$; 95\% CI 0.86-1.28) were not associated with an increased SPC risk. Moreover, although not significant, the SIR increased after one year. SIRs for specific lung cancer types are shown in Table 3.

To estimate the effect of primary $\mathrm{BC}$ treatment on SPC risk, we calculated the SIR of the RT, surgery, and chemotherapy groups. For all treatment modalities except RT, the SPC risk was lower than that in comparable patients with BC. Effects of treatment on SPC risk are summarized in Table 4.

At 21 years follow-up, 22,036 of the 48,875 BC patients had died. The 10-year overall survival (OS) rates were 46.2 and $52.6 \%$ in the SPC and non-SPC groups, respectively $(p=0.000)$. The 5 - and 15 -year OS rates for the SPC group were 72.3 and $28.3 \%$, respectively, whereas those for the non-SPC group were 64.8 and $43.8 \%$, respectively.

The survival curves crossed over time. The SPC group had higher OS rates compared with the non-SPC group for the first 8 years, but the OS of the SPC group declined thereafter (Fig. 1). After the onset of SPC, women had higher OS rates compared with men (Fig. 2).

We conducted a subgroup analysis of the patients treated between 2006 and 2013 to analyze any correlations between the SPC incidence and OS according to the SEER stage which were collected since 2006. After $\mathrm{BC}$ diagnosis, the OS curves of patients with SPC and non-SPC group crossed at 2.5 years (Additional file 1: Figure S1). Moreover, distant staging in SPC and non-SPC groups was estimated at 2.32 and $4.04 \%$ of cases, respectively. For patients with a follow-up of $<2.5$ years, the proportion of distant staging was $5.31 \%$ at diagnosis, whereas that in those followed-up for $\geq 2.5$ years it was $0.8 \%(p=0.000)$. Before 2.5 years, the presence of SPC accounted for $5.38 \%$ of distant stage cases in the non-SPC group, and $3.45 \%$ of cases in the SPC group $(p=0.183)$. Afterwards, the proportions of distant staging were $0.48 \%$ in SPC and $0.82 \%$ in non-SPC group $(p=0.719)$ (Additional file 2: Figure S2).

\section{Discussion}

SIRs for cancers that developed after primary BC were calculated using KCCR data. Analysis of the data revealed that, in the present cohort, $\mathrm{BC}$ survivors had a $6 \%$ lower risk of developing a new malignancy compared with the general population. Cancers of the tongue, tonsils, digestive system (e.g., stomach, colon, and liver) and non-Hodgkin lymphoma were less likely to occur as SPCs in patients with $\mathrm{BC}$. However, these findings were incongruent with those reported previously $[4,5,11]$. While the reasons for reduced SPC risk in the BC patients are unclear, they might be related to smoking cessation and lifestyle modification after a $\mathrm{BC}$ diagnosis. Additionally, these results might, in part, be due to shared etiologies (genetic background and environment) and treatment-related factors [12].

A previous study that evaluated Korean patients with prostate cancer and kidney cancer using similar methods revealed SPC SIRs of 0.75 and 1.13, respectively $[6,7]$. In the present study, the incidences of prostate cancer and kidney cancer were greater. This increased incidence might be due to shared etiological, environmental, and genetic factors between the first and second malignancies [13]. Moreover, a surveillance effect might contribute to increased risk immediately after diagnosis and might explain the elevated prostate cancer and kidney cancer risk after primary $\mathrm{BC}$.

In a study examining associations between urinary tract cancers, Kinoshita et al. demonstrated that BC and prostate cancer share similar traits such as DNA repair and $\mathrm{N}$-acetyl transferase polymorphism [14]. Kellen et al. reported that prostate cancer risk increases in patients $<70$ years old within one year of $\mathrm{BC}$ diagnosis [15]. Lococo et al. also reported a significant increase in the relative risk of kidney cancer following $\mathrm{BC}[16]$.

In this study, we interestingly found that the risk for tongue and tonsil cancer significantly decreased in patients with $\mathrm{BC}$, and the result for tongue cancer is significantly lower in those over 60 compared to those aged 40-59. Chemical factors like tobacco and alcohol, biological factors

Table 3 Risk of SPC by lung cancer histology after BC diagnosis (1993-2013)

\begin{tabular}{|c|c|c|c|c|c|c|}
\hline & \multicolumn{6}{|l|}{ Latency (months) } \\
\hline & Total & & $<12$ & $12-59$ & 60-119 & $\geq 120$ \\
\hline & SIR (O/E) & $95 \% \mathrm{Cl}$ & SIR (O/E) & SIR (O/E) & $\mathrm{SIR}(\mathrm{O} / \mathrm{E})$ & $\mathrm{SIR}(\mathrm{O} / \mathrm{E})$ \\
\hline Lung, bronchus & $1.05(782 / 748.26)$ & $(0.97-1.12)$ & $0.98(90 / 91.90)$ & $1.07(331 / 309.19)$ & $1.03(227 / 220.22)$ & $1.06(134 / 126.96)$ \\
\hline Squamous cell carcinoma & $1.15 \#(280 / 243.85)$ & $(1.02-1.29)$ & $0.94(29 / 30.71)$ & $1.18(121 / 102.47)$ & $1.08(77 / 71.04)$ & $1.34 \#(53 / 39.63)$ \\
\hline Adenocarcinoma & $1.20 \#(221 / 183.65)$ & $(1.05-1.37)$ & $1.39(30 / 21.61)$ & $1.27 \#(94 / 74.26)$ & $1.15(63 / 54.55)$ & $1.02(34 / 33.23)$ \\
\hline Small cell carcinoma & $1.06(99 / 93.82)$ & $(0.86-1.28)$ & $0.69(8 / 11.64)$ & $1.10(43 / 39.13)$ & $1.13(31 / 27.46)$ & $1.09(17 / 15.58)$ \\
\hline Other and unspecified & $0.80 \#(182 / 226.95)$ & $(0.69-0.93)$ & $0.82(23 / 27.95)$ & $0.78 \#(73 / 93.32)$ & $0.83(56 / 67.16)$ & $0.78(30 / 38.51)$ \\
\hline
\end{tabular}

SPC: second primary cancer, $B C$ : bladder cancer, SIR: standardized incidence ratio, Cl: confidence interval, O/E: Observed/Expected

\# significant at alpha $=0.05$ 
Table 4 Risk of SPC according to treatment for primary BC (1993-2013)

\begin{tabular}{|c|c|c|c|c|c|c|}
\hline & RT & Non-RT & Surgery & Non-Surgery & Chemotherapy & Non-chemotherapy \\
\hline & SIR & SIR & SIR & SIR & $\mathrm{SIR}$ & SIR \\
\hline All SPCS & 1.01 & $0.93 \#$ & $0.94 \#$ & $0.85 \#$ & 0.94 & 0.93\# \\
\hline All SPCs excluding BC, KC, pelvic and ureteral cancers & 1.04 & $0.96 \#$ & $0.97 \#$ & $0.86 \#$ & 0.94 & $0.96 \#$ \\
\hline Buccal cavity, pharynx & 0 & 0.80 & 0.83 & 0.35 & 0.56 & 0.82 \\
\hline Tongue & 0 & $0.37 \#$ & 0.40 & 0 & 0.86 & $0.31 \#$ \\
\hline Salivary gland & 0 & 0.94 & 1.01 & 0 & 0 & 1.03 \\
\hline Tonsil & 0 & 0.28 & 0.30 & 0 & 0 & 0.31 \\
\hline Hypopharynx & 0 & 1.21 & 1.30 & 0 & 0.59 & 1.26 \\
\hline Digestive system & 0.88 & $0.85 \#$ & 0.87\# & $0.66 \#$ & $0.78 \#$ & $0.86 \#$ \\
\hline Esophagus & 0.60 & 0.98 & 0.97 & 0.95 & 0.86 & 0.98 \\
\hline Stomach & 0.59 & $0.80 \#$ & 0.81\# & $0.64 \#$ & $0.71 \#$ & $0.80 \#$ \\
\hline Small intestine & 4.18 & 1.38 & 1.49 & 0.79 & 0.68 & 1.51 \\
\hline Colon & 1.35 & $0.83 \#$ & 0.89\# & 0.39\# & 1.04 & $0.82 \#$ \\
\hline Rectum, rectosigmoid junction & 1.20 & 0.91 & 0.91 & 0.90 & 0.87 & 0.92 \\
\hline Anus, anal canal & 0 & 0.99 & 0.86 & 1.98 & 1.86 & 0.87 \\
\hline Liver & 0.98 & 0.79\# & $0.80 \#$ & 0.70 & 0.73 & $0.80 \#$ \\
\hline Gallbladder & 0 & 0.79 & 0.78 & 0.74 & $0.17 \#$ & 0.84 \\
\hline Bile ducts, other biliary & 0.64 & 0.92 & 0.96 & 0.53 & 0.91 & 0.92 \\
\hline Pancreas & 1.4 & 0.97 & 1.01 & 0.69 & 0.62 & 1.02 \\
\hline Respiratory system & 1.16 & 1.05 & 1.05 & 1.01 & 0.98 & 1.06 \\
\hline Nose, nasal cavity, ear & 7.75 & 0.95 & 1.17 & 0 & 1.25 & 1.04 \\
\hline Larynx & 0 & 1.22 & 1.13 & 1.90 & 0.95 & 1.23 \\
\hline Lung, bronchus & 1.18 & 1.04 & 1.05 & 0.97 & 0.98 & 1.05 \\
\hline Female breast & 0 & 1.14 & 1.20 & 0.34 & 0.62 & 1.18 \\
\hline Female genital system & 1.50 & 1.09 & 1.12 & 0.93 & 1.86 & 1.01 \\
\hline Male genital system & $2.23 \#$ & 1.44\# & $1.43 \#$ & 1.74\# & 1.85\# & $1.41 \#$ \\
\hline Prostate & $2.28 \#$ & 1.44\# & 1.43\# & 1.70\# & 1.83\# & $1.41 \#$ \\
\hline Testis & 0 & 4.02 & 4.32 & 0 & 12.33 & 2.95 \\
\hline Urinary system & 1.03 & $0.73 \#$ & $0.69 \#$ & 1.1 & 1.28 & $0.67 \#$ \\
\hline Urinary bladder & 0 & $0.46 \#$ & $0.43 \#$ & 0.61 & 1.03 & $0.38 \#$ \\
\hline Kidney parenchyma & 2.81 & 1.45\# & $1.40 \#$ & 2.29\# & 1.98\# & $1.41 \#$ \\
\hline Renal pelvis, other urinary & 2.43 & $0.24 \#$ & $0.22 \#$ & 0.90 & 0.78 & $0.22 \#$ \\
\hline Brain, central nervous system & 0 & 0.77 & 0.78 & 0.54 & 0 & 0.85 \\
\hline Thyroid & 0 & 1.23\# & $1.23 \#$ & 1 & 1.65 & 1.16 \\
\hline Lymphatic, hematopoietic & 0.46 & $0.76 \#$ & $0.76 \#$ & 0.61 & 0.52 & $0.78 \#$ \\
\hline Hodgkin lymphoma & 0 & 0.79 & 0.84 & 0 & 3.65 & 0.43 \\
\hline Non-Hodgkin lymphoma & 0 & $0.70 \#$ & $0.71 \#$ & 0.50 & 0.42 & $0.72 \#$ \\
\hline Myeloma & 0 & 0.83 & 0.80 & 1.01 & 1.66 & 0.72 \\
\hline Leukemia & 1.53 & 0.81 & 0.85 & 0.58 & $0.00 \#$ & 0.92 \\
\hline
\end{tabular}

$S I R$, standardized incidence ratio, $R T$ : radiotherapy, $B C$ : bladder cancer, SPC: second primary cancer,

$K C$ : kidney cancer, \# significant at alpha $=0.05$

like human papillomavirus (HPV), syphilis, oro-dental factors, dietary deficiencies, chronic candidiasis and viruses have been known to be significantly associated with oral cancer [17]. The mechanism of the declined risk of tongue and tonsil cancer is still unclear. However, we speculated that life style modification (smoking cessation, diet, and so on) may reduce chance of developing tongue and tonsil cancer. 


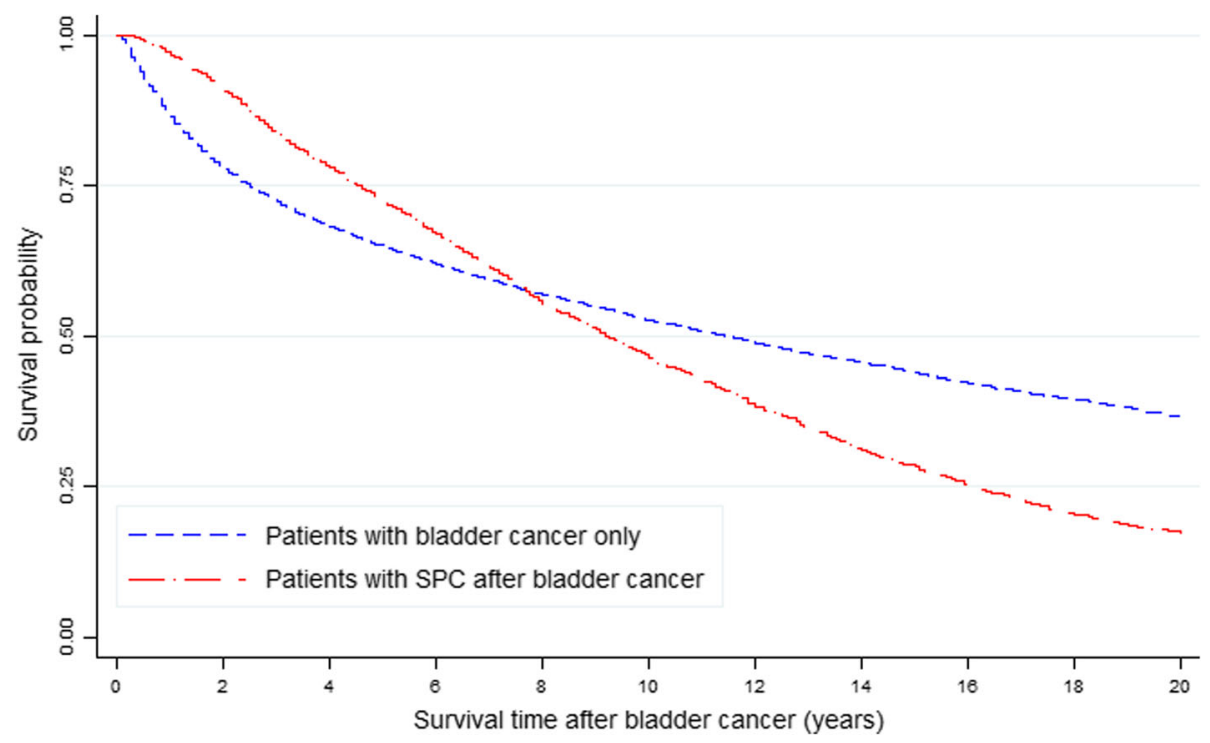

Fig. 1 Kaplan-Meier curve: survival after bladder cancer according to the incidence of second primary cancer (SPC) in all patients

Smoking is a well-known risk factor for BC, kidney, lung, mouth, and pharynx cancers [18] and has been estimated to cause half of all $\mathrm{BC}$ cases in Western countries [19]. In contrast to our hypothesis, the present study did not show an increase in the number of subsequent respiratory system malignancies. Therefore, a sub analysis according to histological lung cancer type was performed, showing a significant increase in the incidence of lung squamous cell carcinoma and adenocarcinoma as SPCs. Possible reasons include potential etiological or genetic background differences between the Western and Asian patients, decreased smoking contribution compared with the West, and the possibility that the other cancers were smoking-related and occurred before the $\mathrm{BC}$ diagnosis.

The risk of cancer caused by radiation follows the individual exposed to radiation and continues to increase throughout the individual's lifetime [20]. Studies evaluating the risk of secondary cancers after radiation therapy for prostate cancer have shown mixed results [21-23]. Recent meta-analyses have shown that patients who received prostate cancer radiotherapy are more likely to have a second malignancy of the bladder, colon and rectum than patients who have not received radiotherapy [24]. To our knowledge, although no studies have reported the risk of secondary cancer after radiation

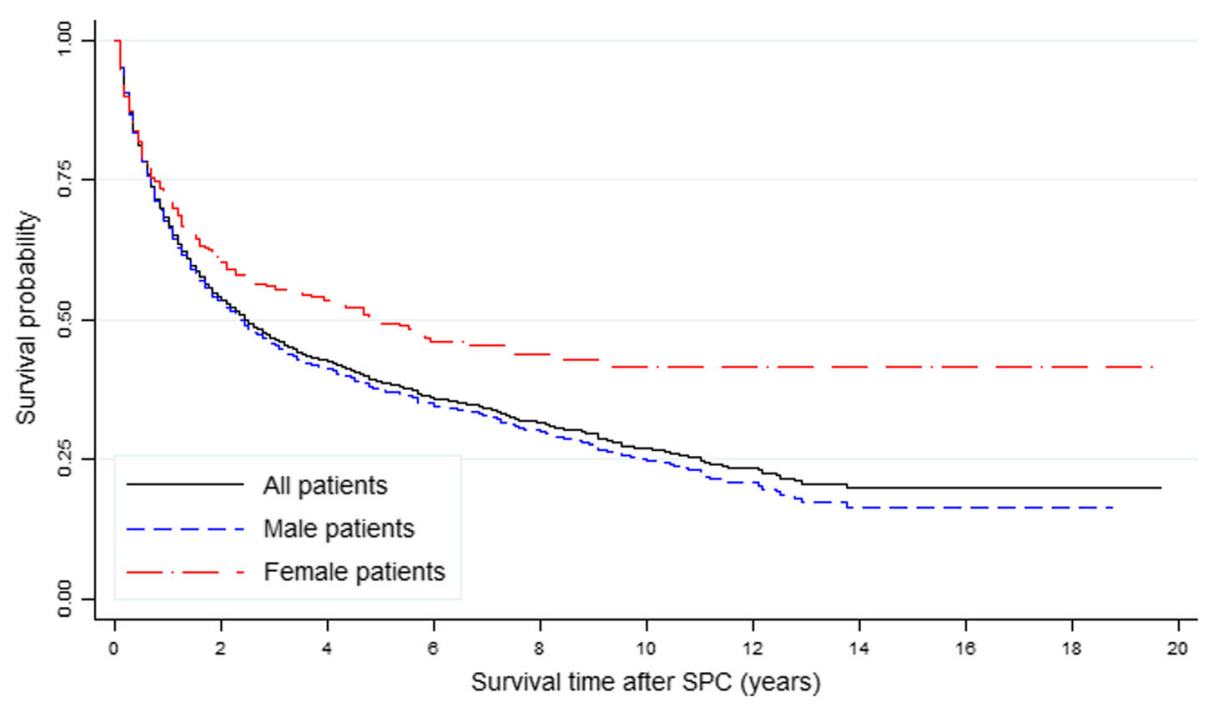

Fig. 2 Kaplan-Meier curve: survival after second cancer according to sex in patients with second cancers 
therapy for bladder cancer, our study showed that secondary cancers were more common in the digestive organs, such as the small intestine, colon, rectum, and female/male genital systems than patients who do not received radiotherapy. We assume that this result is related to the radiation field and is similar to the results of the meta-analysis mentioned above [24]. However, the lack of information such as the specific type of radiation treatment and dose of radiation is another limitation of this study.

To our knowledge, this is the first study to evaluate the histological subtypes of lung cancers as an SPC. Cigarette smoking is an established risk factor for lung cancer, but the severity of its association with other histologic types is unclear. Khuder [25, 26] reported that all histologic lung cancer types were significantly associated with cigarette smoking, and the association was stronger for squamous cell and small cell carcinomas compared with large cell cancer and adenocarcinoma. In the present study, squamous cell carcinoma and adenocarcinoma exhibited a significantly elevated risk of occurring as an SPC. Although not significant, small cell lung cancer risk also increased over an extended follow-up period. If smoking is a shared risk factor for $\mathrm{BC}$ and secondary lung cancer, the influence of smoking on each histologic type of secondary lung cancer in $\mathrm{BC}$ patients might be presumed to be different to that for primary lung cancer.

Cumulative survival curves of patients with or without SPC were estimated to investigate whether SPC affects the survival rate of patients who have BC. In particular, for the first 8 years, the SPC group had superior survival rates compared with the non-SPC group. Overall, this study demonstrated that patients in the non-SPC group had significantly more advanced $\mathrm{BC}$ at the time of diagnosis. Therefore, the survival rate of the non-SPC group was lower than that of the SPC group for the first 2.5 years after diagnosis of $\mathrm{BC}$. Conversely, after 2.5 years the reverse was noted with survival in the SPC group being inferior to that in the non-SPC group. These findings suggested that the SPC group would require more attentive and systemic surveillance after 2.5 years of follow-up.

The present study has several limitations. First, information concerning several potential confounding variables including smoking, alcohol consumption, obesity, and familial cancer history were not available. Second, there was limited data available concerning genetic factors and specific cancer stages among the patients, making it impossible to evaluate the correlation between disease severity and SPC incidence. Third, the higher incidence of SPC might be associated with close surveillance or misclassifications because BC, prostate cancer, and kidney cancer often develop synchronously $[15,16]$. Fourth, the median follow-up period was 4.13 years, which was not relatively long duration. Further studies with long follow-up periods will be needed to estimate the precise risk of developing SPC and to overcome surveillance bias. Fifth, it was impossible to divide into non-muscle invasive cancer and muscle invasive cancer in our study. The survival of patients with bladder cancer may be affected by degree of muscle invasion.

\section{Conclusion}

The risk is lower among Korean survivors of $\mathrm{BC}$ compared to the expected risk of developing SPC in the general population. However, patients with $\mathrm{BC}$ remain at increased risk of some cancers, particularly prostate and kidney, lung squamous cell carcinoma, and lung adenocarcinoma. Therefore, longer and closer surveillance could be recommended for the early detection of SPC.

\section{Additional files}

Additional file 1: Figure S1. Kaplan-Meier curve: survival after bladder cancer (BC) according to the incidence of a second primary cancer (SPC) in all patients (2006-2013). (TIF $1011 \mathrm{~kb}$ )

Additional file 2: Figure S2. Stage distributions by bladder cancer occurrence and follow-up years. (JPG $184 \mathrm{~kb}$ )

\section{Abbreviations}

BC: Bladder cancer; Cl: Confidence interval; KCCR: Korea Central Cancer Registry; RT: Radiotherapy; SD: Standard deviation; SEER: Surveillance epidemiology and end results; SIR: Standardized incidence ratio; SPC: Second primary cancer

\section{Funding}

This work was supported by a research grant from the National Cancer Center (No. 1610201), Republic of Korea. The National Cancer Center had no role in the design of the study, or the collection, analysis, and interpretation of data, or the manuscript preparation.

\section{Availability of data and materials}

All data generated or analyzed during this study are included in this published article.

\section{Authors' contributions}

Conception and design: YJW, WAK, JYJ. Acquisition of data: YJW, CMO, KWJ. Analysis of data: JL, YJW. Drafting of the manuscript: WAK, JYJ, JL, YJW. Critical revision and final approval of the manuscript: All authors read and approved the final manuscript.

Ethics approval and consent to participate

Ethical approval for the research protocol was provided by the institutional review board of the National Cancer Center (NCC2017--0182).

Information was de-identified prior to analysis. The authorization for data processing was obtained from the National Cancer Act.

\section{Competing interests}

The authors declare that they have no competing interests.

\section{Publisher's Note}

Springer Nature remains neutral with regard to jurisdictional claims in published maps and institutional affiliations.

\section{Author details}

${ }^{1}$ Center for Prostate Cancer, National Cancer Center, Goyang, Korea. ${ }^{2}$ Cancer Registration and Statistics Branch, National Cancer Center, Goyang, Korea. 
Received: 28 September 2017 Accepted: 18 May 2018

Published online: 31 May 2018

\section{References}

1. Antoni S, Ferlay J, Soerjomataram I, Znaor A, Jemal A, Bray F. Bladder cancer incidence and mortality: a global overview and recent trends. Eur Urol. 2017;71:96-108.

2. Song $\mathrm{W}$, Jeon $\mathrm{HG}$. Incidence of kidney, bladder, and prostate cancers in Korea: an update. Korean J Urol. 2015:56:422-8.

3. Jung KW, Won YJ, Oh CM, Kong HJ, Lee DH, Lee KH. Cancer statistics in Korea: incidence, mortality, survival, and prevalence in 2014. Cancer Res Treat. 2017:49:292-305.

4. Wilson RT, Silverman DT, Fraumeni Jr JF, Curtis RE. New malignancies following cancer of the urinary tract. In: Curtis RE, Freedman DM, Ron E, LAG R, Hacker DG, Edwards BK, et al., editors. New malignancies among cancer survivors: SEER cancer registries. Bethesda MD: National Cancer Institute; 1973. p. 285-312.

5. Jegu J, Colonna M, Daubisse-Marliac L, Tretarre B, Ganry O, Guizard AV, et al. The effect of patient characteristics on second primary cancer risk in France. BMC Cancer. 2014;14:94.

6. Joung JY, Lim J, Oh CM, Jung KW, Cho H, Kim SH, et al. Risk of second primary cancer among prostate cancer patients in Korea: a populationbased cohort study. PLoS One. 2015;10:e0140693.

7. Joung JY, Kwon WA, Lim J, Oh CM, Jung KW, Kim SH, et al. Second primary cancer risk among kidney cancer patients in Korea: a population-based cohort study. Cancer Res Treat. 2018:50:293-301.

8. Shin HR, Won YJ, Jung KW, Kong HJ, Yim SH, Lee JK, et al. Nationwide cancer incidence in Korea, 1999 2001; first result using the national cancer incidence database. Cancer Res Treat. 2005;37:325-31.

9. Fritz A, Percy C, Jack A, Shanmugaratnam K, Sobin L, Parkin DM, Whelan S. International classification of diseases for oncology. Lyon, France: World Health Organization; 2000.

10. Curado MP, Okamoto N, Ries L, Sriplung H, Young J, Carli P-M, et al. International rules for multiple primary cancers (ICD-0 third edition). Eur J Cancer Prev. 2005;14(4):307-8

11. Muller J, Grosclaude P, Lapotre-Ledoux B, Woronoff AS, Guizard AV, Bara S, et al. Trends in the risk of second primary cancer among bladder cancer survivors: a population-based cohort of 10047 patients. BJU Int. 2016;118:53-9.

12. Wood ME, Vogel V, Ng A, Foxhall L, Goodwin P, Travis LB. Second malignant neoplasms: assessment and strategies for risk reduction. J Clin Oncol. 2012; 30:3734-45.

13. Boice JD Jr, Storm HH, Curtis RE, Jensen OM, Kleinerman RA, Jensen HS, et al. Introduction to the study of multiple primary cancers. Natl Cancer Inst Monogr. 1985;68:3-9.

14. Kinoshita $Y$, Singh A, Rovito PM Jr, Wang CY, Haas GP. Double primary cancers of the prostate and bladder: a literature review. Clin Prostate Cancer. 2004;3:83-6.

15. Kellen E, Zeegers MP, Dirx M, Houterman S, Droste J, Lawrence G, et al. Occurrence of both bladder and prostate cancer in five cancer registries in Belgium, the Netherlands and the United Kingdom. Eur J Cancer. 2007:43:1694-700.

16. Lococo F, Galeone C, Sacchettini C, Leuzzi G, Cesario A, Paci M, et al. Second malignancy risk in patients with bronchopulmonary carcinoids: epidemiological results from Italian network of Cancer registries. Tumori. 2017;103:e15-20.

17. Ram H, Sarkar J, Kumar H, Konwar R, Bhatt ML, Mohammad S. Oral cancer: risk factors and molecular pathogenesis. J Maxillofac Oral Surg. 2011;10:132-7.

18. Dreyer L, Winther JF, Pukkala E, Andersen A. Avoidable cancers in the Nordic countries. Tobacco smoking APMIS Suppl. 1997;76:9-47.

19. Brennan P, Bogillot O, Cordier S, Greiser E, Schill W, Vineis P, et al. Cigarette smoking and bladder cancer in men: a pooled analysis of 11 case-control studies. Int J Cancer. 2000;86:289-94.

20. Preston DL, Ron E, Tokuoka S, Funamoto S, Nishi N, Soda M, et al. Solid cancer incidence in atomic bomb survivors: 1958-1998. Radiat Res. 2007;168:1-64.

21. Berrington de Gonzalez A, Curtis RE, Kry SF, Gilbert E, Lamart S, Berg CD, et al. Proportion of second cancers attributable to radiotherapy treatment in adults: a cohort study in the US SEER cancer registries. Lancet Oncol. 2011; 12:353-60

22. Brenner DJ, Curtis RE, Hall EJ, Ron E. Second malignancies in prostate carcinoma patients after radiotherapy compared with surgery. Cancer. 2000; 88:398-406.
23. Zelefsky MJ, Pei X, Teslova T, Kuk D, Magsanoc JM, Kollmeier M, et al. Secondary cancers after intensity-modulated radiotherapy, brachytherapy and radical prostatectomy for the treatment of prostate cancer: incidence and cause-specific survival outcomes according to the initial treatment intervention. BJU Int. 2012;110:1696-701.

24. Wallis CJ, Mahar AL, Choo R, Herschorn S, Kodama RT, Shah PS, et al. Second malignancies after radiotherapy for prostate cancer: systematic review and meta-analysis. BMJ. 2016;352:1851.

25. Khuder SA. Effect of cigarette smoking on major histological types of lung cancer: a meta-analysis. Lung Cancer. 2001;31:139-48.

26. Khuder SA, Dayal HH, Mutgi AB, Willey JC, Dayal G. Effect of cigarette smoking on major histological types of lung cancer in men. Lung Cancer. 1998;22:15-21.

\section{Ready to submit your research? Choose BMC and benefit from:}

- fast, convenient online submission

- thorough peer review by experienced researchers in your field

- rapid publication on acceptance

- support for research data, including large and complex data types

- gold Open Access which fosters wider collaboration and increased citations

- maximum visibility for your research: over $100 \mathrm{M}$ website views per year

At BMC, research is always in progress.

Learn more biomedcentral.com/submissions 